\title{
Thresholds in the sliding resistance of simulated basal ice
}

\author{
L. F. Emerson and A. W. Rempel \\ 1272 University of Oregon, Department of Geological Sciences, Eugene, OR 97403, USA
}

Received: 18 June 2007 - Published in The Cryosphere Discuss.: 29 June 2007

Revised: 1 October 2007 - Accepted: 15 October 2007 - Published: 25 October 2007

\begin{abstract}
We report laboratory determinations of the shear resistance to sliding melting ice with entrained particles over a hard, impermeable surface. With higher particle concentrations and larger particle sizes, Coulomb friction at particlebed contacts dominates and the shear stress increases linearly with normal load. We term this the sandy regime. When either particle concentration or particle size is reduced below a threshold, the dependence of shear resistance on normal load is no longer statistically significant. We term this regime slippery. We use force and mass balance considerations to examine the flow of melt water beneath the simulated basal ice. At high particle concentrations, the transition from sandy to slippery behavior occurs when the particle size is comparable to the thickness of the melt film that separates the sliding ice from its bed. For larger particle sizes, a transition from sandy to slippery behavior occurs when the particle concentration drops sufficiently that the normal load is no longer transferred completely to the particle-bed contacts. We estimate that the melt films separating the particles from the ice are approximately $0.1 \mu \mathrm{m}$ thick at this transition. Our laboratory results suggest the potential for abrupt transitions in the shear resistance beneath hard-bedded glaciers with changes in either the thickness of melt layers or the particle loading.
\end{abstract}

\section{Introduction}

An understanding of the factors that control how ice deforms and slides is crucial for predicting how glaciers and ice sheets will respond to changing climate conditions. The inaccessibility of glacier beds makes it particularly challenging to quantify the resistance to glacier sliding. We conducted laboratory experiments to examine the frictional resistance exerted between a hard, impermeable surface (glass) and melting ice that contained known quantities and size distributions

Correspondence to: A. W. Rempel

(rempel@uoregon.edu) of entrained sediment particles. As particle size or concentration increased we observed abrupt transitions between low shear-resistance, fluid-dominated behavior and high shearresistance, particle-dominated behavior. We show that geometric requirements for the flow of melt water from the sliding surface can explain these phenomena.

This study is motivated by an interest in the frictional resistance beneath hard-bedded glaciers. A brief review of the controlling mechanisms for sliding beneath debris-free glacier ice is in order. Of primary importance are the size and spacing of bedrock obstacles. Ice deformation accommodates flow over large, widely spaced obstacles, whereas short-wavelength bed irregularities are traversed by the process of melting and refreezing known as regelation (Weertman, 1957, 1964; Nye, 1969, 1970; Kamb, 1970; Lliboutry, 1968). This combination of processes implies that obstacles of intermediate size (e.g. typically of m-scale, Paterson, 1994, p. 136) provide the most significant resistance to sliding. The assertion that it is the shape of the bed that controls sliding has served as the basis for theoretical treatments of glacial abrasion and erosion (Shoemaker, 1988; Hallet 1979a, 1981; Boulton, 1979). Laboratory demonstrations of the control exerted by bed irregularities on sliding resistance have helped to corroborate these theories (Chadbourne et al., 1975; Budd et al., 1979). More recent theoretical work suggests that cavitation on the lee side of bedrock obstacles may even lead to sliding instabilities by reducing glacier-bed coupling at high sliding rates (Schoof, 2005).

The influence of entrained sediments on the resistance to glacier sliding is not well understood, though the common observation of bedrock striations attests to the potential significance of this component of the sliding resistance. Boulton (1974) postulated that the frictional resistance between the glacier bed and entrained debris is proportional to the volume fraction of entrained sediment, as is appropriate if the total normal stress supported by bed-particle contacts is proportional to their areal coverage. Hallet (1979a) suggested that viscous flow and regelation of ice around entrained debris

Published by Copernicus Publications on behalf of the European Geosciences Union. 
Table 1. Observed friction coefficients for each ice type (third column). Italicized friction coefficients indicate slopes that cannot be differentiated from zero at the $95 \%$ confidence interval. The regression intercept for these cases is close to the mean measured shear stress across the experiments. All regressions based on 15 datum points except where noted by superscript, a: 14 points; b: 12 points.

\begin{tabular}{|c|c|c|c|c|c|}
\hline $\begin{array}{l}\text { particle } \\
\text { size } \\
(\mathrm{mm})\end{array}$ & $\begin{array}{l}\text { particle } \\
\text { concentration } \\
(\mathrm{wt} \%)\end{array}$ & $\begin{array}{l}\text { regression } \\
\text { slope } \\
\mu\end{array}$ & $\begin{array}{l}\text { standard } \\
\text { error of } \\
\mu\end{array}$ & $r^{2}$ & $\begin{array}{l}\text { regression } \\
\text { intercept } \\
(\mathrm{Pa})\end{array}$ \\
\hline 0.00 & 0 & $-0.0002^{a}$ & 0.0005 & 0.02 & 7.1 \\
\hline 0.01 & 2.5 & $0.0009^{a}$ & 0.008 & 0.11 & 12 \\
\hline 0.02 & 2.5 & -0.004 & 0.003 & 0.15 & 46 \\
\hline 0.05 & 2.5 & 0.004 & 0.01 & 0.011 & 130 \\
\hline 0.10 & 2.5 & $-0.001^{b}$ & 0.02 & 0.0005 & 190 \\
\hline 0.18 & 2.5 & 0.22 & 0.04 & 0.66 & 140 \\
\hline 0.34 & 2.5 & 0.30 & 0.04 & 0.78 & -120 \\
\hline 0.75 & 2.5 & 0.32 & 0.04 & 0.85 & -51 \\
\hline 1.5 & 2.5 & 0.42 & 0.03 & 0.95 & -31 \\
\hline 0.34 & 0.01 & $0.005^{b}$ & 0.004 & 0.16 & 31 \\
\hline 0.34 & 0.05 & 0.002 & 0.02 & 0.001 & 140 \\
\hline 0.34 & 0.10 & 0.04 & 0.02 & 0.26 & 140 \\
\hline 0.34 & 0.25 & 0.03 & 0.03 & 0.06 & 240 \\
\hline 0.34 & 0.5 & 0.08 & 0.04 & 0.23 & 220 \\
\hline 0.34 & 1.0 & 0.24 & 0.04 & 0.75 & -34 \\
\hline 0.34 & 2.5 & 0.30 & 0.04 & 0.78 & -120 \\
\hline 0.34 & 5.0 & 0.23 & 0.02 & 0.88 & -27 \\
\hline 0.34 & 10 & 0.24 & 0.04 & 0.76 & -23 \\
\hline 0.34 & sandy disk & $0.38^{a}$ & 0.02 & 0.97 & -17 \\
\hline
\end{tabular}

determines the effective normal stress borne by bed-particle contacts, in which case the frictional resistance should be proportional to the rate of melting and increase with the size of entrained particles. Using the subglacial access tunnel at Engabreen, Norway, Iverson et al. (2003) showed that the shear tractions imparted to the bed by sediment entrained in the overlying glacier ice can be much greater than either of these theories would predict. Cohen et al. (2005) developed a model that is consistent with the Engabreen observations, based on the hypothesis that ice deformation around entrained debris controls the effective normal stress at bed-particle contacts. Other laboratory studies have focused on the ability of sediment-laden cold $\left(<-10^{\circ} \mathrm{C}\right)$ ice to abrade (Mathews, 1979), and the influence of "plowing" by entrained particles on the resistance to glacier sliding over water-saturated sediments (Thomason and Iverson, 2004), but none have investigated how sediment entrained in the ice may control the resistance to sliding over hard-bedded glaciers at the pressure melting point.

These experiments explore how sliding behavior changes with variations in the size and concentration of entrained particles. In the following section we describe our experimental set-up and procedure. Next, we present our results, which demonstrate abrupt changes in sliding resistance at thresholds of particle size and particle concentration. We interpret these results using simple models based on the conservation laws and well-established concepts from lubrication theory (e.g., Batchelor, 1994, pp 219-222). We then discuss the relevance of our laboratory results to natural glacier sliding and offer a few concluding remarks.

\section{Experimental method}

We made 18 simulated basal "ice types" that mimic the regelation layer of Kamb and LaChapelle (1964). Eight were used to test the effect of particle size (median particle sizes: $0.01 \mathrm{~mm}, 0.02 \mathrm{~mm}, 0.05 \mathrm{~mm}, 0.10 \mathrm{~mm}, 0.18 \mathrm{~mm}$, $0.34 \mathrm{~mm}, 0.75 \mathrm{~mm}, 1.5 \mathrm{~mm}$; all with particle concentration $2.5 \mathrm{wt} \%)$, nine were used to test the effect of particle concentration $(0.01 \mathrm{wt} \%, 0.05 \mathrm{wt} \%, 0.10 \mathrm{wt} \%, 0.25 \mathrm{wt} \%, 0.50 \mathrm{wt} \%$, $1.0 \mathrm{wt} \%, 2.5 \mathrm{wt} \%, 5.0 \mathrm{wt} \%$, and $10.0 \mathrm{wt} \%$; all with median particle size $0.34 \mathrm{~mm}$ ), and the final was a "clean ice" control with no added particles (see Table 1). The sediment was sieved Willamette River, OR, USA sand and contained subangular to sub-rounded quartz, feldspar, mica and lithic fragments. Sediment particles were evenly distributed throughout the ice volume as follows: i) crushed ice (fragments up to approximately $5 \mathrm{~mm}$ in size) was mixed with the chosen particles and loaded in a columnar freezing vessel $(108 \mathrm{~mm}$ inner diameter), ii) the mixture was saturated with water and this residual liquid was frozen; iii) the simulated basal ice was removed from the freezing vessel and cut into disks 


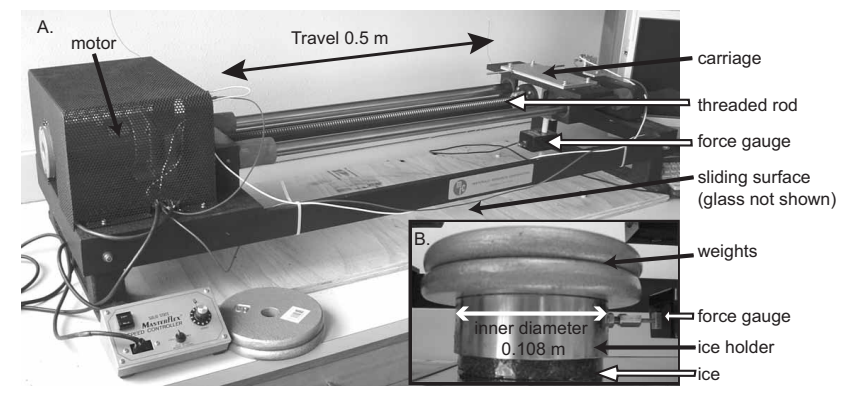

Fig. 1. (A) Experimental apparatus. The motor turns a threaded rod which drives the carriage. The force-gauge height is adjusted to account for small differences in ice-disk thickness. (B) Ice disks are placed in the ice holder ( $240 \mathrm{~g})$ and attached to the force gauge by a doubled threaded nut. Weights are used to adjust the normal force.

$\left(0.0094 \mathrm{~m}^{2}\right.$ surface area). In addition to the simulated basal ice, we made 5 "sandy" control disks by gluing $0.34 \mathrm{~mm}$ particles to foam-board.

We built an apparatus (see Fig. 1) to slide the ice over a pane of glass and measure the shear resistance. We conducted all experiments at room temperature $\left(22 \pm 2^{\circ} \mathrm{C}\right)$. Ice was constantly melting and the melt-water flowed freely from beneath the ice disk. We weighed the ice when it was removed from the freezer and after the sliding experiments to determine the vertical melt rate $(10 \mu \mathrm{m} / \mathrm{s}$ (mean) $\pm 3 \mu \mathrm{m} / \mathrm{s}$ (std. dev.)). Each disk slid in the apparatus three times: first with no additional imposed mass, second with $2.25 \mathrm{~kg}$ on top of the ice holder, and third with $4.5 \mathrm{~kg}$. The ice holder itself has a mass of $0.24 \mathrm{~kg}$. A total displacement of $\sim 0.3 \mathrm{~m}$ was traversed at a constant velocity of $8.7 \mathrm{~mm} / \mathrm{s}$. For each run, force-gauge data were collected for $40 \mathrm{~s}$ with a sampling frequency of $50 \mathrm{~Hz}$. Each $40 \mathrm{~s}$ record included a short period with the ice at rest followed by approximately $35 \mathrm{~s}$ of sliding. The results reported here are based on $15 \mathrm{~s}$ sampling windows from 17-32 s of the recorded data, examples of which are shown in Fig. 2. The experimental procedure was repeated five times, each time with a new ice disk. This allowed for 15 shear force averages per ice type and control. To confirm that displacement history was not a controlling factor in our results the loading order was reversed for two sets of experiments and no behavioral change was observed. The large number of averaged independent data points ensured that the standard errors in the measured shear forces were small. We note, however, that stick-slip cycles of increasing and decreasing shear stress values were observed on sub-second time scales (Fig. 2).

\section{Results}

For each ice type and control we plotted the shear $(\tau)$ vs. the normal $(N)$ stress and performed linear regressions, as shown in Fig. 3. We used the slope and its standard error to calculate

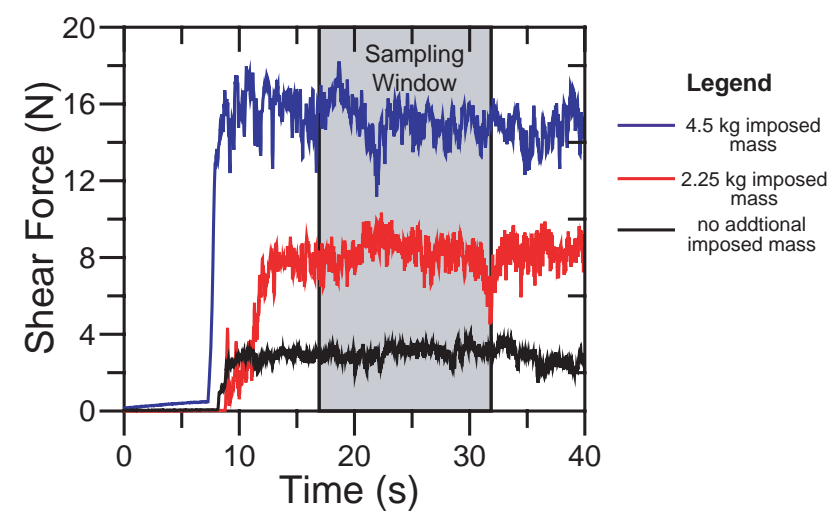

Fig. 2. Sample shear force data (5 point running average) for one of the ice disks with particle concentration $2.5 \mathrm{wt} \%$ and particle diameter $0.75 \mathrm{~mm}$. The different lines correspond to measurements made with the labeled normal loads. The grey box shows the duration over which the data was averaged to calculate $\mu$ : 750 datum points.

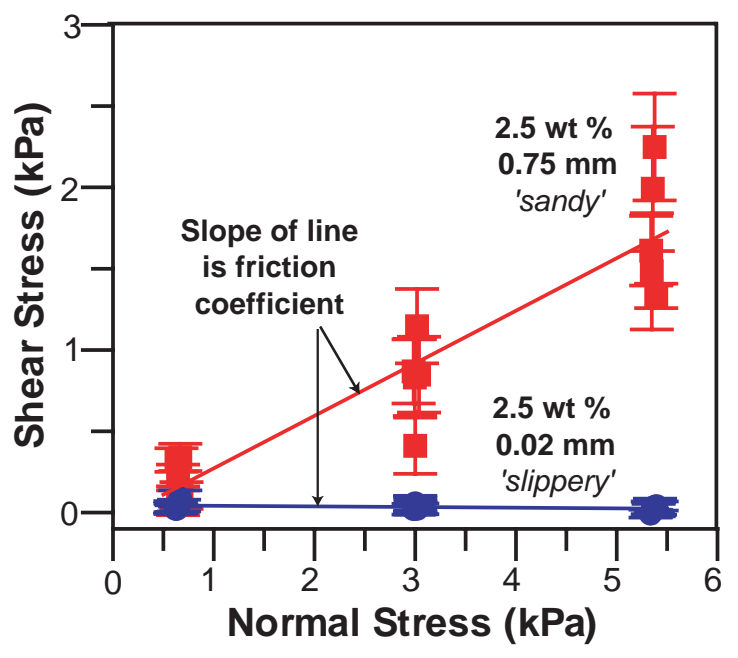

Fig. 3. Measured shear stress as a function of normal stress for two "ice types". One shows sandy behavior (red), $\mu=0.32$, and the other slippery (blue), $\mu=-0.004$. Error bars are one standard deviation of the shear stress above and below the mean.

the significance of each regression. Our data fall into two distinct regimes (see Fig. 3 and Table 1) that we term: sandy and slippery.

Data in the sandy regime are characterized by significant regressions (at the $95 \%$ confidence level), which indicate that the measured shear stress is dependent on normal stress. The slope of the regression line is the friction coefficient $\mu$. All ice types with median particle diameters $\geq 0.18 \mathrm{~mm}$ and/or concentrations $\geq 1.0 \mathrm{wt} \%$, as well as the sandy control disks were in this regime. We report the regression intercepts in Table 1 as well. In the sandy regime, intercept magnitudes are small in comparison to the mean shear stress and there is 

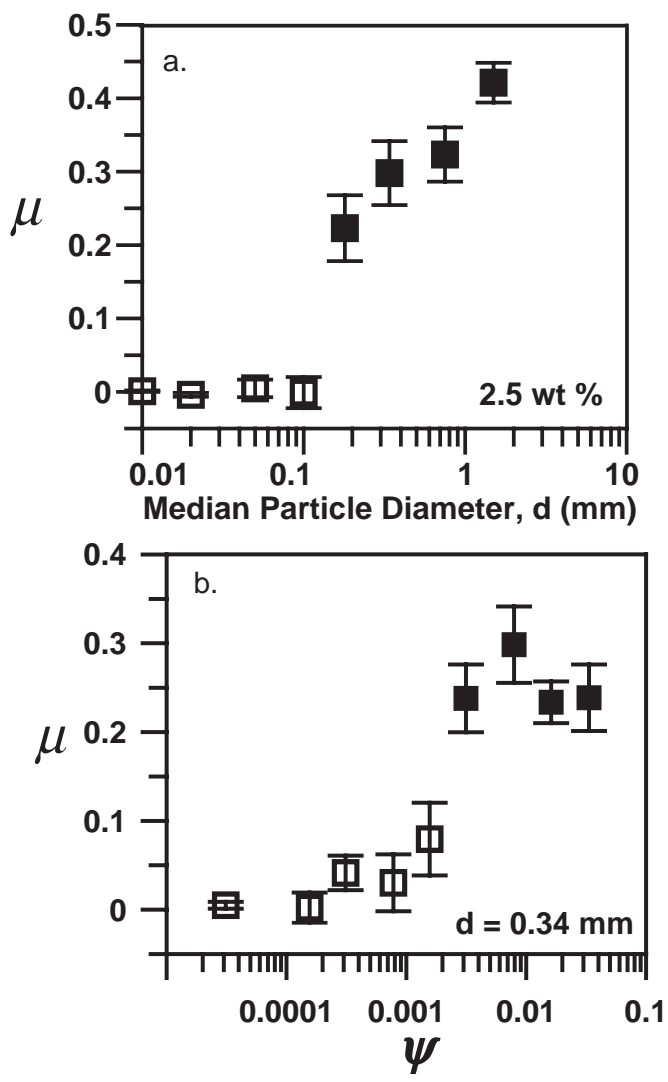

Fig. 4. Friction coefficient as a function of (a) particle diameter, and (b) particle concentration $\psi$. Solid boxes indicate $\mu$ derived from regressions that are significant (non-zero) at the $95 \%$ confidence level, hollow boxes indicate values derived from regressions that fall below this significance threshold. Error bars are the standard error of the slope.

no significant difference in slope when regressions are forced through the origin.

The slopes of the data regressions in the slippery regime were not significantly different from zero, indicating that shear stress is independent of normal stress in these cases. This makes the calculation of a friction coefficient dubious. We do, however, for the sake of comparison display the values obtained in Fig. 4. All ice types with median particle diameters $\leq 0.1 \mathrm{~mm}$ and/or concentrations $\leq 0.5 \mathrm{wt} \%$, as well as the debris-free ice control, were in the slippery regime (Fig. 4, Table 1). In the slippery regime, the regression intercept is close to the mean measured shear stress and can be identified with cohesive behavior. At constant particle concentration there is a clear increase in intercept with particle size. At constant particle size, the trend appears to be for higher intercept values with increased particle concentration.

As shown in Fig. 4, abrupt transitions between the slippery and sandy regime occur when either the particle size or the particle concentration crosses a threshold. While these thresholds are easy to identify and statistically significant, there is also some scatter in our experimental data (e.g., see Fig. 3). We attempted to keep experimental conditions as controlled and uniform as possible. However, inhomogeneous mixing and particle settling prior to freezing of the ice disks were probably responsible for some of this scatter. Since the ice was melting over the course of the experiments, slight differences to the sliding surface undoubtedly took place as well. Some particles that began the experiments completely encapsulated by ice were introduced to the sliding surface later as the ice melted from beneath them. Some particles that began on the sliding surface were dislodged and left behind. Based on the short duration of each sliding experiment and the measured melting rates, we infer that these changes could only have affected a small fraction of the total number of particles on the sliding surface. They may, nevertheless, have been responsible for some of the experimental scatter.

\section{Interpretation}

The resistance to basal sliding is determined by the nature of the ice-bed contact. In our experiments, the melting ice provides a continuous supply of water to the sliding surface. The low-viscosity melt film produces very little shear resistance, as confirmed by the low shear forces recorded for the clean ice controls (see Table 1). Hence, the low effective friction coefficients $(<0.1)$ observed in the slippery regime suggest that water at the ice base controls the sliding behavior and particle-bed contacts bear only a small fraction of the normal load. By contrast, when sediment particles entrained in the ice effectively couple to the bed, the shear resistance increases in proportion to the normal stress and the sandy regime is attained. Significant (non-zero) friction coefficients $(>0.2)$ observed in the sandy regime suggest that particle-bed contacts bear most of the normal load.

\subsection{Threshold behavior with increased particle size}

The experimental results show that there is a critical particle size $(\sim 0.1 \mathrm{~mm})$ above which the shear stress depends on the normal stress and a meaningful friction coefficient can be determined (Fig. 4a). We expect this size to be determined by the thickness of the melt film that separates the ice from the underlying bed. Particles that are close to or smaller than the thickness of the melt film cannot remain effectively coupled to the ice while in contact with the bed and are therefore incapable of bearing a significant fraction of the normal load. This intuition is confirmed by ignoring particles and calculating the approximate melt-film thickness $h$. As described in the appendix, we estimate $h$ by considering the vertical force balance beneath an ice disk of diameter $D$ that is melting at rate $Q$. The pressure distribution in the melt water 


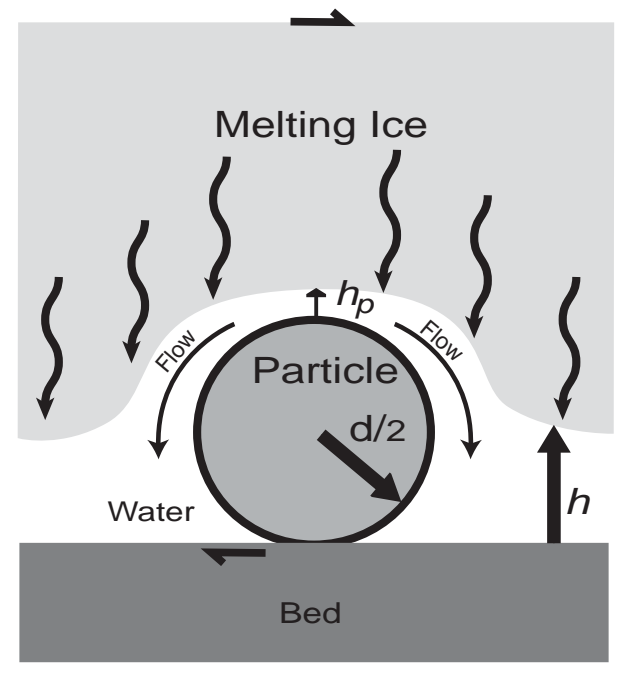

Fig. 5. Schematic diagram of the sliding system in the vicinity of particle-bed contacts. We use force and mass balance considerations to estimate fluid thickness directly above a particle, $h_{p}$, and far from particles, $h$, as described in the text.

that is required to support the normal stress $N$ and maintain a steady-state configuration is

$h=\left(\frac{3 \eta Q D^{2}}{8 N}\right)^{1 / 3}$,

where $\eta=0.0018 \mathrm{Pas}$ is the liquid viscosity. This yields a value of approximately 40 microns for our typical experimental conditions (e.g. $Q=10 \mu \mathrm{m} / \mathrm{s}, D=0.1 \mathrm{~m}, N=1 \mathrm{kPa}$ ). This is comparable to, but somewhat smaller than the threshold particle size determined from our experiments. We attribute the difference to the formation of melt channels on the ice base that help to flush smaller particles from the system, as observed in video footage filmed through the glass sliding surface from below.

\subsection{Threshold behavior with increased particle concentra- tion}

Even when the particle size is large in comparison to the thickness of the melt film that separates the ice from the sliding surface, our experiments indicate that a significant friction coefficient is only attained once the particle concentration $\psi$ exceeds a critical level (Fig. 4,b). At very low particle concentrations, the low shear resistance we measure indicates that only a small fraction of the normal load is transferred to the particle-bed contacts. The magnitude of stresstransfer to the particles is determined by the distribution of elevated fluid pressures in the very thin melt films, of thickness $h_{p}$, that separate particles from the overlying ice. As shown in Fig. $5, h_{p}$ is generally expected to be different from the film thickness $h$ that separates the ice and sliding surface away from the particles. At low particle concentrations, we

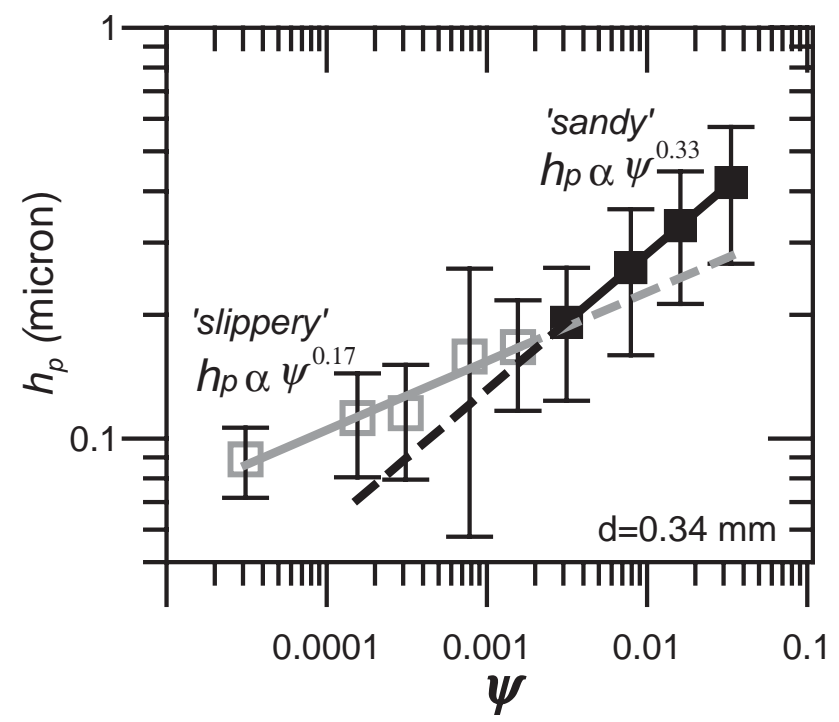

Fig. 6. The average calculated thickness $h_{p}$ as a function of particle concentration for each of the ice types with $d=0.34 \mathrm{~mm}$. Filled squares are the sandy regime ice-types with particle concentration $\geq 0.1 \mathrm{wt} \%$ ( $\psi=0.0031)$. Open squares are slippery regime ice-types with concentration $\leq 0.05 \mathrm{wt} \%(\psi=0.0015)$. Solid lines are best-fit power-laws, with the labeled exponents. The students t-test indicates that the exponents are different at a $>99 \%$ confidence level.

deduce that the melt films above the particles do not become thin enough for the fluid pressures to reach the high values needed to transfer the entire normal load to the particle-bed contacts.

For further insight, we consider the balance of forces on a sediment particle of diameter $d$ that is in frictional contact with the sliding surface, as shown schematically in Fig. 5. The normal load transferred to the particle is inferred from the measured shear resistance $\tau$, volumetric particle concentration $\psi$, and an estimate of the effective particle-glass friction coefficient, $\mu_{p}=0.38$, taken from the experiments with the sandy control disks. To a very good approximation, this normal load is balanced by the fluid pressure distribution in a thin premelted film that separates the particle from the overlying ice. As discussed further in the appendix, the thickness of this film $h_{p}$ is estimated as

$h_{p}=\left(\frac{\mu_{p} \psi \eta Q d^{2}}{\tau}\right)^{1 / 3}$.

In Fig. 6 we plot the calculated values of $h_{p}$ as a function of $\psi$ for the experiments summarized in Fig. $4 \mathrm{~b}$. The film thickness $h_{p}$ above the particles is always a small fraction of $h$ - the estimated ice-disk separation far from the particles (typically $40 \mu \mathrm{m}$, see above), and in fact $h_{p}<1 \mu \mathrm{m}$ for all of the experimental data we collected. At large $\psi$ the best-fit power law indicates that $h_{p} \propto \psi^{0.33}$. With more dilute particle concentrations $h_{p} \propto \psi^{0.17}$, which indicates that the fluid 
pressure away from the particle-glass contacts must support part of the normal load, e.g. $\tau / \mu_{p}<N$. Striations produced in the glass by the harder particles suggest that the effective friction coefficient at smaller particle concentrations may actually have been somewhat higher because of the additional shear resistance required to produce these indentations. If a higher value of $\mu_{p}$ were used at low $\psi$, the exponent in the power-law fit would be reduced further below its calculated low-concentration value of 0.17 . This supports the hypothesis that $h_{p}$ tends to a lower bound as the particle concentration is reduced. The minimum $h_{p}$ inferred from our experiments is approximately $0.1 \mu \mathrm{m}$, though a weak dependence on $\psi$ does appear to persist to the lowest concentrations that we could reliably attain with our experimental set-up.

\section{Discussion and conclusions}

The abrupt thresholds that we observe in the frictional behavior of simulated basal ice occur within the range of particle sizes and concentrations that are found in glaciers (e.g., Kamb and LaChapelle, 1964). However, our experiments were performed at rates of melting and sliding that are much more rapid than those that commonly occur in nature. Both ice deformation and pressure regelation - the two mechanisms that enable glacier flow over rough beds - are too slow to be effective with our laboratory set-up. Nevertheless, the melt-dominated regime that we consider here improves our understanding of potential mechanisms for thresholds in frictional behavior within natural glacier systems.

The thicknesses of the melt films that separate glacier ice from the underlying bedrock are expected to be highly variable, both spatially and temporally (e.g., Hallet, 1979b). For example, with $D$ reinterpreted as the typical distance between subglacial channels or bedrock fractures that enable efficient melt-water drainage, Eq. (1) gives estimates for $h$ ranging from $1-30 \mu \mathrm{m}$ for $D$ between $10 \mathrm{~cm}$ and $10 \mathrm{~m}$ with $Q=100 \mathrm{~mm} / \mathrm{a}$ and $N=10 \mathrm{kPa}$. This is sufficiently small that most entrained debris should easily span such ice-bed gaps. Areas of much greater ice-bed separation are likely to be encountered on the lee-side of bedrock obstacles, and in these regions only the larger particles are expected to make frictional contact.

The observed dependence of frictional resistance on particle concentration is more difficult to interpret. We infer that the thicknesses of the premelted films that separated the ice from the particles in our experiments were not able to thin sufficiently for the fluid pressure to transmit the entire load once $h_{p}$ reached about $0.1 \mu \mathrm{m}$. Equation (2) predicts that films of such thickness are reached above $\mathrm{cm}$-scale particles once $\psi$ reaches about $2 \%$ when $Q=100 \mathrm{~mm} / \mathrm{a}$ and $\tau / \mu_{p}=10 \mathrm{kPa}$. The effective friction-coefficients that operate beneath glaciers (e.g., Iverson et al., 2003) are typically much lower than rock-on-rock friction coefficients (e.g., Byerlee, 1978), so it is clear that the magnitude of stress-transfer to entrained particles is not normally able to support the entire normal load. We have no theoretical justification for why $h_{p}=0.1 \mu \mathrm{m}$ should be a limiting film size - only the observation that it seems to act as such in our experiments. At the low melt rates encountered beneath glaciers, regelation and ice deformation may well control the magnitude of stress transfer to entrained particles (e.g., Hallet, 1981; Cohen et al., 2005). In either case, the stress transfer requires elevated fluid pressures in the melt above the particles, with the implied presence of flow restrictions such as those that would be provided by film thicknesses that are much smaller above the particles than away from the particle-bed contacts. For comparison, the prediction of Boulton (1974) that debris-bed friction should be proportional to $\psi$ is consistent with the expectation that the film thicknesses above and away from particles are essentially the same. Persistent variations in film thickness could be explained by the existence of persistent temperature gradients or by persistent compositional gradients in the melt films (Shreve, 1984) - neither of which are easy to justify. Nevertheless, the repeatability of our experiments and the enhanced role of particle-bed frictional coupling observed in the field (e.g., Iverson et al., 2003) do raise the intriguing possibility of threshold sliding behavior in nature with changes in particle concentration.

Variations in the hydraulic regime under glaciers are likely to modify the distance between the ice and its bed. When the separation increases, for example, bedrock irregularities are "drowned" and a smaller percentage of the heterogeneously sized sediment carried by a glacier is capable of coupling the ice to the bed. This can lead to reduced frictional resistance through both the particle-size and particle-concentration dependent mechanisms observed here. Reduced frictional resistance may contribute to faster sliding rates that further enlarge subglacial cavities and reduce particle-bed coupling. Conversely, decreases in water pressure that produce reductions in melt-film thickness can enhance the frictional coupling and possibly lead to reductions in sliding rate. Additionally, sediment concentration may vary through time as ice deforms around sediment and bedrock obstacles. When sediment loading is close to threshold values, the frictional behavior we observe suggests the potential for rapid velocity fluctuations.

In our experiments, the primary controls on frictional resistance are the size of entrained particles in relation to the thickness of the fluid layer that separates ice from the bed, and the efficiency of stress-transfer across the melt layers that overly the particles themselves. Particles that are too small or too dilute provide little frictional resistance, but abrupt increases in frictional resistance occur as size and concentration are increased beyond threshold values. The wide variability of particle-loading in basal glacier ice suggests that similar frictional thresholds may be encountered in nature. 


\section{Appendix A}

\section{Slippery regime film thickness}

For small particles, the low shear resistance we measure is interpreted to imply that the normal load is almost entirely supported by the melt film beneath the ice and the sediment particles do not play a significant role. In our experiments, the particles only occupy a small fraction of the ice surface. We estimate the thickness of the melt film beneath the ice by considering the case of an idealized, smooth, particle-free, ice disk. Since the film is thin, we use the lubrication approximation to the Navier-Stokes equations, which stipulates that all flow is parallel to the ice and glass surfaces, the pressure gradients that drive flow are also radial, and inertial effects are negligible so that the equation governing fluid flow is

$\eta \frac{\mathrm{d}^{2} u}{\mathrm{~d} z^{2}}=\frac{\mathrm{d} P}{\mathrm{~d} r}$

where $u$ is the fluid velocity, $\eta$ is the viscosity, $P$ is fluid pressure, and $z$ and $r$ are the vertical and radial coordinates (with the origin located immediately beneath the center of the ice disk on the glass surface). We integrate this equation twice with respect to $z$ to get the fluid velocity profile

$u=-\frac{1}{2 \eta} \frac{\mathrm{d} P}{\mathrm{~d} r} z(h-z)$,

where we have substituted in for the integration constants by making use of the no-slip boundary conditions on the glass surface at $z=0$ and on the ice surface, where $z=h$. If we consider a ring of radius $r$ that is centered at the origin, then the total flux of fluid $q$ that passes by is equal to the circumference of the ring times the integral of the fluid velocity over the thickness of the film

$q=2 \pi r \int_{0}^{h} u \mathrm{~d} z=-\frac{\pi r}{6 \eta} h^{3} \frac{\mathrm{d} P}{\mathrm{~d} r}$.

We consider a steady state in which the film thickness is constant so that this flux is supplied by melting. If the melt rate $Q$ is constant over the surface of the ice then we expect that $q=-\pi r^{2} Q$. Solving for the pressure gradient, we have that

$\frac{\mathrm{d} P}{\mathrm{~d} r}=\frac{6 \eta Q}{h^{3}} r$.

The fluid pressure at the edge of the disk where $r=D / 2$, is atmospheric so the fluid pressure beneath the slider can be written as

$$
P=-\int_{D / 2}^{r} \frac{6 \eta Q}{h^{3}} r \mathrm{~d} r=\frac{3 \eta Q}{h^{3}}\left(\frac{D^{2}}{4}-r^{2}\right) .
$$

The force imparted on the ice disk by this fluid pressure distribution is equal to the normal force so

$N \pi \frac{D^{2}}{4}=2 \pi \int_{0}^{D / 2} r P \mathrm{~d} r$ which implies a film thickness of

$h=\left(\frac{3 \eta Q D^{2}}{8 N}\right)^{1 / 3}$.

\section{Appendix B}

\section{Premelted film thickness over particles}

A thin premelted film is assumed to separate each particle from the overlying ice. We can evaluate the thickness of the film by considering the force balance on the particle. The experiments give us the measured shear stress $\tau$ as a function of the normal load $N$. Since the viscous resistance to shearing the melt film away from the particles is small (as gauged by the experiments with the clean ice control), we assume that the measured shear stress can be attributed to the frictional resistance at the particle-bed contacts. The effective normal load borne by particles of diameter $d$ and volumetric concentration $\psi$ is

$F_{e}=\frac{\pi d^{2} \tau}{4 \mu_{p} \psi}$,

where $\mu_{p}$ is the effective friction coefficient of the particlebed contact. When the particles bear the entire normal load we expect that $F_{e}=\pi d^{2} N /(4 \psi)$, but $F_{e}$ can be lower than this when the fluid pressure in the melt film distant from the particles bears a significant fraction of the load.

There are two sources of downwards forces on the particle. The first of these is probably more important in our experimental configuration. This is the force that is produced by the distribution of fluid pressures around the particle. The melt generated above the particle must flow around it, and the fluid pressure gradient in the film above the particle that is associated with this flow produces a net force on the particle surface that can be written as (Rempel and Worster, 1999, Eq. 9)

$F_{\mu}=\frac{3}{4} \pi d^{4} \eta Q \int_{0}^{\theta_{c}} \sin \theta \cos \theta\left(\int_{\theta_{c}}^{\theta} \frac{\sin \phi}{l^{3}} \mathrm{~d} \phi\right) \mathrm{d} \theta$,

where $\theta_{c}$ is a cut-off angle which is set to a value where the film thickness $l(\theta)$ is much bigger than at the apex (the precise value of this angle is not important to the calculations since the dominant contributions to the integrals come from angles near zero).

In order for the fluid pressure to be elevated and transmit significant loads to the particles, the premelted film thickness $l$ must be smaller immediately above the particles than the far-field film thickness $h$ that separates the ice from the glass surface in regions where particles are distant. As Shreve (1984) recognized, thinner melt films beneath glaciers imply that the temperature of the ice-liquid interface is depressed from the normal bulk melting temperature $T_{m}$ and 
here this premelting behavior suggests that the temperature above the particles is slightly lower than in regions where the film thickness is $h$. We assume that the temperature gradient $G$ is linear and the film thickness follows a power-law dependence on temperature (e.g., Wettlaufer and Worster, 1995; Dash et al., 2006) so that

$\frac{\lambda^{3}}{l^{3}}=\frac{\lambda^{3}}{h^{3}}+\frac{G}{T_{m}}\left[\frac{d}{2}-h+\left(\frac{d}{2}+h\right) \cos \theta\right]$,

where $\lambda$ is a length scale that characterizes the strength of the intermolecular interactions that cause premelting. We define the film thickness immediately above the particles as $h_{p}$ and consider the limit where $h_{p} \ll d / 2$ and $h_{p} \ll h$ to find that

$F_{\mu} \approx \pi d^{3} \eta Q\left(1-\frac{h}{d}\right)^{2} \frac{(d+h)}{4 h_{p}^{3}}$.

As noted earlier, in many circumstances we expect that $F_{\mu}$ and $F_{e}$ will be much bigger than any other vertical forces in the problem. Equating the two, we anticipate that

$h_{p} \approx\left[\frac{\mu_{p} \psi \eta d^{2} Q}{\tau}\left(1-\frac{h}{d}\right)^{2}\left(1+\frac{h}{d}\right)\right]^{1 / 3}$.

In cases where $h \ll d$, this simplifies further to

$h_{p} \approx\left(\mu_{p} \psi \eta Q \frac{d^{2}}{\tau}\right)^{1 / 3}$.

Further analysis shows that intermolecular forces produce a significant contribution to the vertical force balance that results in an increase to the film thickness when the length scale

$\lambda \gg\left(\frac{3 d^{2} \eta Q}{4 L}\right)^{1 / 3}$,

where $L \approx 300 \mathrm{MJ} / \mathrm{m}^{3}$ is the latent heat of fusion per volume. During a typical experiment with $d=0.34 \mathrm{~mm}$ and $Q=10 \mu \mathrm{m} / \mathrm{s}$, we are justified in neglecting the net force produced by intermolecular interactions as long as $\lambda<17 \mathrm{~nm}$. Typical values are an order of magnitude or more smaller (e.g., $\lambda=0.5 \mathrm{~nm}$ was reported by Wettlaufer and Worster, 1995) and we neglect these effects in our treatment.

Acknowledgements. We thank John Logan for his encouragement and support. We also thank Denis Cohen and Andrew Rathbun for helpful reviews. Funding was received from the University of Oregon and NSF OPP0440841.

Edited by: J. O. Hagen

\section{References}

Batchelor, G. K.:, An Introduction to Fluid dynamics, Cambridge University Press, Cambridge, 1994.

Boulton, G. S.: Processes and Patterns of Glacial Erosion, in: Glacial Geomorphology: London, edited by: Coates, D. R., George Allen and Unwin, p. 41-89, 1974.

Boulton, G. S.: Processes of glacier erosion on different substrata, J. Glaciol., 23(89), 15-38, 1979.

Budd, W. F., Keage, P. L., and Blundy, N. A.: Empirical Studies of Ice Sliding, J. Glaciol., 23(89), 157-170, 1979.

Byerlee, J.: Friction of Rocks, Pure. Appl. Geophys., 116, 615-626, 1978.

Chadbourne, B. D., Cole, R. M., Tootill, S., and Walford, M. E. R.: The movement of melting ice over rough surfaces, J. Glaciol., 14(71), 287-292, 1975.

Cohen, D., Iverson, N. R., Hooyer, T. S., Fischer, U. H., Jackson, M., and Moore, P. L.: Debris-bed friction of hard-bedded Glaciers, J. Geophys. Res., 110, F02007, doi:10.1029/2004JF000228, 2005.

Dash, J. G., Rempel, A. W., and Wettlaufer, J. S.: The physics of premelted ice and its geophysical consequences, Rev. Mod. Phys., 78(3), 695-741, 2006.

Hallet, B.: A theoretical model of glacial abrasion, J, Glaciol., 23(89), 39-50, 1979a.

Hallet, B.: Subglacial regelation and water film, J. Glaciol., 23(89), 321-334, 1979b.

Hallet, B.: Glacial abrasion and sliding: their dependence on the debris concentration in Basal ice, Ann. Glaciol., 2, 23-28, 1981.

Iverson, N. R., Cohen, D., Hooyer, T. S., Fischer, U. H., Jackson, M., Moore, P. L., Lappegard, G., and Kohler, J.: Effects of Basal Debris on Glacier Flow, Science, 301, 81-84, 2003.

Kamb, B.: Sliding motion of glaciers: Theory and observation, Rev. Geophys. Space Ge., 8, 4, 673-728, 1970.

Kamb, B. and LaChapelle, E.: Direct observation of the mechanism of glacier sliding over bedrock, J. Glaciol., 5(38), 159-172, 1964.

Lliboutry, L.: General theory of subglacial cavitation and sliding of temperate glaciers, J. Glaciol., 7(49), 21-58, 1968.

Mathews, W. H.: Simulated Glacial Abrasion, J. Glaciol., 23(89), 51-55, 1979.

Nye, J. F.: A calculation on the sliding of ice over a wavy surface using a Newtonian viscous approximation, P. Roy. Soc. A-Math. Phys., 311, 1506, 445-467, 1969.

Nye, J. F.: Glacier sliding without cavitation in a linear viscous approximation, Proc. P. Roy. Soc. A-Math. Phys., 315, 1522, 381403, 1970.

Paterson, W. S. B.: The Physics of Glaciers, Pergamon Press Ltd., London, 1994.

Rempel, A. W. and Worster, M. G.: The interaction between a particle and an advancing solidification front, J. Cryst. Growth, 205, 427-440, 1999.

Schoof, C.: The effect of cavitation on glacier sliding, P. Roy. Soc. A-Math. Phys., 461, 609-627, 2005.

Shreve, R. L.: Glacier sliding at subfreezing temperatures, J. Glaciol., 30(106), 341-347, 1984.

Shoemaker, E. M.: On the formulation of basal debris drag for the case of sparse debris, J. Glaciol., 34(118), 259-264, 1988.

Thomason, J. and Iverson, N.: Clast plowing as a potential flow instability for soft-bedded glaciers, EOS Trans. AGU, 85, 47, Fall Meet. Suppl., Abstract C31B-0327, 2004. 
L. F. Emerson and A. W. Rempel: The sliding resistance of simulated basal ice

Weertman, J.: On the sliding of glaciers, J. Glaciol., 3, 33-38, 1957. Weertman, J.: The theory of glacier sliding, J. Glaciol., 5, 39, 287303, 1964.
Wettlaufer, J. S. and Worster, M. G.:, Dynamics of premelted films: Frost heave in capillary, Phys. Rev. E, 51(5), 4679-4689, 1995. 